\title{
Psicologia Histórico-Cultural e desenvolvimento da atenção voluntária: novo entendimento para o TDAH
}

\author{
Hilusca Alves Leite \\ Silvana Calvo Tuleski
}

\section{Resumo}

Este artigo discute o desenvolvimento da atenção voluntária de acordo com a Psicologia Histórico-Cultural, tendo o intuito de possibilitar nova compreensão do Transtorno de Déficit de Atenção/Hiperatividade (TDAH). Compreensão esta que vai de encontro às concepções hegemônicas a respeito do problema, entendido como decorrente de desajustes no organismo do sujeito. Para o texto apresentado, primeiramente, foi feita uma exposição deste entendimento predominante sobre o assunto, destacando dados a respeito da venda de medicamentos para tratar casos de TDAH e problemas relacionados ao diagnóstico deste. Em seguida, apresenta-se a compreensão de desenvolvimento humano para a Psicologia Histórico-Cultural, dando ênfase ao desenvolvimento da atenção voluntária e às possibilidades de superação da concepção hegemônica sobre o TDAH que esta teoria apresenta. Conclui-se que a perspectiva teórica utilizada possibilita não apenas um novo olhar para os problemas de desatenção e comportamentos hiperativos, mas também novo planejamento de práticas capazes de promover o desenvolvimento da atenção. Palavras-chave: Transtorno de déficit de atenção/hiperatividade, atenção, Psicologia histórico-cultural.

\section{Historical-Cultural Psychology and development of voluntary attention: new understanding about the ADHD}

\begin{abstract}
In this article we discuss the development of voluntary attention based on Historical-Cultural Psychology, aiming at a new understanding of Attention Deficit Hyperactivity Disorder (ADHD). This goes against the hegemonic conceptions regarding the problem, understood as caused by dysfunction in one's organism. In this work we first make an exposition of this predominant ideas on the subject, detaching data regarding the medicine sales to deal with cases of ADHD and problems related to the its diagnosis. Later we present the understanding of human development in Historical-Cultural Psychology, emphasizing the development of the voluntary attention, and the possibilities of overcoming the hegemonic conception of ADHD. We conclude that the employed theoretical perspective makes possible not only a new way to look at problems of attention deficit and hyperactive behaviors, but also proposes new practices capable of promoting attention development.
\end{abstract}

Key-words: Attention deficit hyperactivity disorder, attention, historic-cultural psychology.

\section{Psicología Histórico-Cultural y desarrollo de la atención voluntaria: nueva comprensión para el TDAH}

\section{Resumen}

Este artículo discute el desarrollo de la atención voluntaria de acuerdo con la Psicología Histórico-Cultural, con el fin de posibilitar nueva comprensión del Trastorno de Déficit de Atención e Hiperactividad (TDAH). Esta compresión va en contra de las concepciones hegemónicas al respecto del problema, entendido como consecuencia de desajustes en el organismo del sujeto. En el texto presentado, en primer lugar, se hizo una exposición de la comprensión predominante sobre el tema, destacando datos al respecto de la venta de medicamentos para tratar casos de TDAH y problemas relacionados a su diagnóstico. En seguida, se presenta la comprensión de desarrollo humano para la Psicología HistóricoCultural, dándose énfasis al desarrollo de la atención voluntaria y a las posibilidades de superación de la concepción hegemónica sobre el TDAH que esta teoría presenta. Se concluye que la perspectiva teórica utilizada posibilita no sólo una nueva forma de ver los problemas de desatención y comportamientos hiperactivos, sino también nueva planificación de prácticas capaces de promover el desarrollo de la atención.

Palabras Clave: Trastorno de déficit de atención e hiperactividad, atención, psicología histórico-cultural. 


\section{Introdução}

Este artigo propõe expor a respeito de como se dá o desenvolvimento da atenção voluntária na abordagem da Psicologia Histórico-Cultural. Entende-se que conhecer como se desenvolve este tipo de atenção, especialmente na referida perspectiva teórica, oferece subsídios para fazer contraposição à concepção predominante a respeito dos problemas de atenção e controle voluntário do comportamento, conhecidos hegemonicamente como Transtorno de déficit de atenção/hiperatividade (TDAH). O texto aqui apresentado é resultado de uma pesquisa realizada no mestrado em Psicologia. Esta teve como objetivo principal o estudo do desenvolvimento da atenção voluntária no entendimento da Psicologia Histórico-Cultural (Leite, 2010).

Antes de abordar a questão do desenvolvimento da atenção, é necessário esclarecer o que se entende como a visão hegemônica do TDAH. A definição mais difundida para o problema é aquela encontrada no Manual Diagnóstico e Estatístico de Transtornos Mentais (DSM-IV). Conforme o manual, o transtorno "consiste num padrão persistente de desatenção e/ou hiperatividade-impulsividade, mais frequente e grave do que aquele tipicamente observado nos indivíduos em nível equivalente de desenvolvimento" (DSM-IV-TR, 2003, p. 112).

As explicações para esse padrão persistente de desatenção, frequentemente, recaem sobre desajustes no organismo do indivíduo. Atualmente, a ideia mais propagada e aceita é a de que indivíduos com TDAH têm problemas na transmissão e recaptação de neurotransmissores como a norepinefrina e a dopamina, especialmente deste último. As áreas do córtex que estariam envolvidas nessa "falha" com os neurotransmissores seriam os lobos frontais (Barkley, 2008; Brown, 2007).

O entendimento de que o TDAH é um problema de origem orgânica vem servindo de base para que se acredite que sua etiologia seja genética, tendo transmissão hereditária. É importante destacar que a origem genética do problema não está completamente confirmada, no entanto, pesquisas nesta direção servem para reforçar a opinião de que o ambiente não contribui para o desenvolvimento do problema. Além disso, tal compreensão fortalece a ideia de que o melhor - talvez único - tratamento é aquele à base de medicamentos (Barkley, 2008; Brown, 2007; Moraes, Silva, \& Andrade, 2007; Souza, Serra-Pinheiro, \& Fortes, 2007; entre outros).

De acordo com Barkley (2008), o tratamento pode ser feito com antidepressivos tricíclicos, atomexina (ainda não disponível no Brasil), anti-hipertensivos, e metilfenidato, sendo este último o mais comercializado, conhecido popularmente com o nome de Ritalina. Conforme o Instituto Brasileiro de Defesa de Medicamentos (IDUM), os gastos entre os brasileiros com a compra de medicamento para TDAH, somente no ano de 2008 , chegaram a 88 milhões de reais. Sobre o comércio especificamente do metilfenidato, o instituto observa que, dos anos de 2000 a 2008, no Brasil, as vendas cresceram $1.616 \%$. Somente no ano de 2008 no
Brasil, foram vendidas 1.147 .000 caixas deste medicamento (IDUM, 2009).

O metilfenidato é uma droga estimulante que tem a capacidade de ativar o nível de atividade, excitação ou alerta no sistema nervoso central. Age no cérebro bloqueando a recaptação de um neurotransmissor chamado dopamina durante as transmissões sinápticas. Com mais dopamina no córtex, os sintomas de impulsividade e hiperatividade ficam reduzidos, permitindo que o indivíduo controle seu comportamento e, consequentemente, "dirija" sua atenção (Connor, 2008). Assim sendo, infere-se que os benefícios promovidos pelo metilfenidato seriam interessantes, especialmente no contexto de sala de aula, em que se espera que o aluno fique sentado prestando atenção no professor.

No entanto, é importante destacar também que o metilfenidato provoca efeitos colaterais que vão desde os mais brandos, como perda do apetite, náuseas, cefaleia, perda do sono, tristeza e irritabilidade, até os mais severos, como convulsões, alucinações, tiques, problemas no crescimento e, em alguns casos, pode causar dependência (Goldstein \& Goldstein, 1996; IDUM, 2009).

Soma-se a esse quadro de crescente venda de medicamentos para TDAH, os casos de diagnósticos realizados de forma superficial. O diagnóstico para o transtorno recomendado pelo DSM-IV é eminentemente clínico, baseado nas questões propostas pelo manual, e deve ter a avaliação de um médico. Como forma de apoio ao que foi "detectado" a partir do DSM-IV, recomenda-se a aplicação de testes psicométricos, em geral o Wisc III ${ }^{1}$, para fornecer dados e auxiliar na conclusão do diagnóstico (Argollo, 2003; Knapp, Rohde, Lyszkowski, \& Johannpeter, 2002). Também se recomenda que sejam feitos exames de neuroimagens, capazes de identificar alterações no funcionamento do cérebro (Mattos e cols., 2006). No entanto, é possível questionar a proposta apresentada pelo manual para constatação do TDAH. O manual traz uma série de questões que, em geral, suscitam respostas subjetivas e bastante genéricas, bem como critérios que não condizem com a tentativa de se afirmar que o problema da desatenção tem origem orgânica².

Além disso, pesquisa realizada por Eidt (2004), na qual procurou investigar como vinham sendo feitos os diagnósticos para TDAH na saúde pública em crianças de uma cidade de São Paulo, demonstra que, na prática, a realidade é outra. A autora constatou que não se exige uma análise mais criteriosa do contexto da criança, apenas busca-se enquadrá-la nos sintomas listados pelo DSM-IV. Muitos

\footnotetext{
1 Escala de inteligência Wechsler (Wisc III). Teste que visa medir a capacidade intelectual das crianças.

2 A título de exemplificação, reproduz-se aqui uma das questões propostas pelo manual: "Com frequência tem dificuldade para organizar tarefas e atividades?". Trata-se de uma das perguntas relacionadas à desatenção em crianças, porém é difícil definir o que é essa "frequência" pedida pelo manual, pois o que certos indivíduos consideram frequente, outros podem não considerar. $E$ mais, a simples constatação feita através de perguntas cujas respostas são absolutamente subjetivas seria suficiente para determinar que o indivíduo diagnosticado tem um problema orgânico?
} 
diagnósticos, 33,63\% dos 352 prontuários observados pela autora, eram feitos com apenas uma única sessão.

Há ainda casos em que os diagnósticos são realizados a partir de "ensaios terapêuticos". Nestes, o profissional que avalia a criança baseia-se nos sintomas aparentes para prescrever a medicação recomendada para os casos de TDAH e, se o paciente responder bem a medicação, isto é, se os sintomas forem atenuados, constata que o paciente realmente tem o transtorno (Eidt, 2004).

A autora demonstra, ainda, que os profissionais apresentavam dificuldades na realização do diagnóstico diferencial ${ }^{3}$ frente a outros quadros, bem como divergências sobre as formas de avaliação e intervenções mais adequadas para cada caso. Dessa maneira, muitas vezes, crianças com dificuldades na escola ou indisciplinadas recebiam o diagnóstico de TDAH. Juntamente com a falta de diagnóstico diferencial entre o que seria de fato o transtorno e o que seria indisciplina escolar, a prática do ensaio terapêutico acaba por favorecer que crianças indisciplinadas sejam indevidamente diagnosticadas e medicadas como portadoras do TDAH, "promovendo a 'medicalização' e a naturalização das dificuldades escolares" (Eidt, 2004, p. 182).

Diante do exposto até aqui, entende-se ser importante propor outra compreensão a respeito do problema da desatenção e dos comportamentos hiperativos, pautada em uma perspectiva teórica que faça frente à evidenciada acima, de cunho estritamente organicista, sendo que os caminhos buscados para este enfrentamento foram as elaborações da Psicologia Histórico-Cultural.

\section{Do "reflexo de orientação" à atenção voluntária: o caminho de humanização proposto pela Psicologia Histórico-Cultural}

L. S. Vigotski ${ }^{4}$ (1896-1934), psicólogo soviético que, juntamente com A. R. Luria (1902-1977) e A. N. Leontiev (1903-1979), desenvolveu a teoria da Psicologia Histórico-Cultural, considerava que o comportamento humano deveria ser estudado tanto nos seus aspectos biológicos quanto históricos, pois mudanças no desenvolvimento histórico da humanidade criavam um tipo diferente de homem. Tais mudanças se dão tanto na relação dos homens com os demais homens quanto do homem com a natureza. Neste processo, a própria natureza do homem se modifica e se desenvolve (Vigotski \& Luria, 1996a).

Seguindo essa linha de raciocínio, Luria (1986) compreendia a atividade humana, caracterizada pelo trabalho social, como um primeiro fator criador de novas formas de comportamento. Embora a estrutura biológica do homem

\footnotetext{
3 Realizar um diagnóstico que descarte a possibilidade de que os sintomas apresentados não se enquadrem em algum outro transtorno. Este é um dos critérios diagnósticos exigidos pelo DSMIV.

4 Existem diferentes grafias para o nome deste autor. Optouse por esta forma - "Vigotski" - por ser a que mais se aproxima do português. No entanto, quando forem utilizadas obras deste, manter-se-á a escrita conforme se apresenta na obra consultada.
}

não tenha sofrido grandes alterações, por meio da atividade vital humana (trabalho), altera-se a forma de compreender o mundo e de se relacionar com os outros homens.

Ao elaborar instrumentos de trabalho para agir sobre a natureza, o homem, além de modificar a natureza, modifica o seu próprio comportamento, sua estrutura interna, seu psiquismo. O trabalho, por ser uma atividade mediada pelos instrumentos criados pelo próprio homem, vai além de qualquer atividade desenvolvida por outras espécies, pois confere ao homem certa autonomia em relação à natureza em virtude da capacidade de antecipação dos resultados de suas ações, escolhendo o melhor caminho para atingir determinados fins (Konder, 1985).

Além disso, o trabalho proporcionou a ampliação dos agrupamentos humanos - quando consideramos a filogênese - possibilitando o convívio em sociedade e garantindo a sobrevivência dos grupos. Para Vygotski (1930/2004), o homem só existe enquanto indivíduo por se tornar social, por fazer parte de um grupo social inserido em um contexto histórico. A personalidade, o comportamento e o caráter de um indivíduo estão estreitamente vinculados aos aspectos do grupo ao qual esse indivíduo pertence. "Cada pessoa é em maior ou menor grau o modelo da sociedade, ou melhor, da classe a que pertence, já que nela se reflete a totalidade das relações sociais" (Vigotski, 1927/1996, p. 368). Assim, para Vigotski, a compreensão do homem singular deve partir primeiramente do entendimento do contexto sociocultural ao qual este homem pertence, pois, segundo o autor, personalidade, caráter e comportamento de um indivíduo têm íntima ligação com a evolução social, com os aspectos do grupo e, fundamentalmente, com as relações sociais de produção.

O método de investigação proposto por Vigotski, chamado de método instrumental, busca compreender de que maneira o emprego de instrumentos e signos possibilitam ao homem dominar o meio externo e também a sua própria conduta. Tal investigação se deu tanto no plano da ontogênese quanto da filogênese. Isto é, o autor se preocupou em desenvolver uma metodologia de análise que contemplasse a compreensão da trajetória de transformação dos aspectos biológicos/instintivos em culturais/sociais em um indivíduo singular (ontogênese); bem como compreender as alterações ocorridas na evolução das espécies em seus aspectos biológicos que possibilitaram o surgimento da hominização, tendo como resultado posterior a transformação gradual do homem primitivo em homem cultural em seu aspecto filogenético (Vigotski \& Luria, 1996a).

Vigotski não concebia que se estudassem tais linhas de desenvolvimento em separado, mas como uma ruptura dada na linearidade biológica e, ao mesmo tempo, um salto qualitativo na direção da história humana, condicionada pelo desenvolvimento e aperfeiçoamento dos instrumentos e signos (Vigotski \& Luria, 1996a). Deste modo, a superação por incorporação do orgânico ao desenvolvimento histórico-cultural nada mais é do que a defesa deste autor em relação à impossibilidade de se dissociar a unidade do individual/ social e do biológico/cultural. 
Do exposto, depreende-se que, se cada vez mais são encontrados indivíduos desatentos e hiperativos, pode-se pensar que a sociedade atual, a partir das especificidades das relações sociais de produção hoje vigentes e dos processos educativos delas derivados, vem produzindo sujeitos com tais características. A pergunta que emerge é: que relações de produção são estas, que vêm produzindo indivíduos sem "foco atencional" ou "sem autocontrole"? Qual o critério que se estabelece nesta forma de produção de comportamentos para se distinguir entre o saudável e o patológico? As respostas a tais indagações foram buscadas nas relações entre a esfera política e econômica nas quais todos estão inseridos e na implicação delas no trabalho e na educação, o que será explorado mais adiante, ainda que brevemente.

\section{O processo de desenvolvimento da atenção: do interpsicológico para o intrapsicológico}

Os estudos de Vigotski demonstram que as formas superiores de comportamento estão alicerçadas sobre as formas inferiores. As condutas inferiores são inatas, os comportamentos reflexos ou instintivos, por exemplo. Já as superiores, voluntárias, precisam ser desenvolvidas, e, para isso, é necessária a participação do sujeito em um meio cultural. Ao se desenvolver, a forma superior aparentemente volta a se converter em inferior, ou seja, torna-se automatizada. Isso ocorre porque os elementos mediadores que fizeram surgir a forma superior de comportamento foram internalizados (Vygotski, 1931/2000a). Pode-se citar, como exemplo, a criança em processo de alfabetização. No início, ela precisa soletrar as letras enquanto escreve, pois o som das letras ajuda a mediar o processo de escrita. Após dominar esse processo, tais sons ficam internalizados e a escrita torna-se mais rápida e automatizada.

Ao estudar o desenvolvimento psíquico, Vygtoski (1931/2000a) defendia que se fizesse a análise das funções psíquicas do ponto de vista dinâmico. Tal análise se dá por meio do entendimento do processo de "nascimento" de uma determinada função superior. Nesse sentido, entender o TDAH dentro desta perspectiva teórica implica em ir além do estudo dos sintomas mais evidentes ou primários (desatenção, hiperatividade e impulsividade) e também da concepção de que os indivíduos têm, naturalmente, a capacidade de prestar atenção e controlar seu comportamento; é necessário, antes, estudar como ocorre o desenvolvimento da atenção, especialmente da forma superior de atenção (a voluntária), para então discutir possíveis "falhas" que implicam em problemas considerados como o déficit de atenção. $\mathrm{E}$, de acordo com esse método, ao discutir tais "falhas", há que se buscar compreender a origem delas, principalmente na situação social de desenvolvimento do indivíduo em questão.

O autor afirma que toda função psíquica superior foi primeiramente externa, porque ocorreu em uma relação social entre duas pessoas. Assim, toda função que não é inata na criança aparece duas vezes, primeiramente no plano social - interpsicológico - e, mais adiante, enquanto função psicológica internalizada - intrapsicológica. Isso ocorre com todas as funções superiores: atenção voluntária, memória lógica, formação de conceitos, desenvolvimento da vontade (Vygotski, 1931/2000b).

Para que ocorra a internalização, isto é, a transposição do meio inter para o intrapsicológico, de uma função superior, é imprescindível que haja mediação. Ao nascer, a criança encontra um ambiente dado, mas não é capaz de compreendê-lo como algo criado por homens, utiliza-o conforme recebe indicações para fazê-lo (Markus, 1974). A partir dessas indicações, terá inicio o processo de desenvolvimento das funções superiores.

No caso do desenvolvimento da atenção, que é o foco deste artigo, tem-se, inicialmente, que este é considerado um processo puramente orgânico "de crescimento, maturação e desenvolvimento dos aparatos nervosos e das funções da criança" (Vygotski, 1931/2000c, p. 214). Vigotski salienta que este processo de maturação é fundamental no primeiro ano de vida da criança e não se interrompe ao longo de toda infância, nem mesmo na vida adulta. No entanto, conforme ocorre o desenvolvimento, tal processo passa a ser dirigido por fatores socioculturais. Ocorre um processo de superação da fase mais primitiva por incorporação às mais complexas, decorrentes da interação do indivíduo com seu ambiente sociocultural, que lhe impõe tarefas para as quais necessitará da regulação efetiva de seu comportamento e atenção.

A forma mais elementar de manifestação da atenção é chamada atenção involuntária. Esta é considerada um fenômeno natural e tem, em sua base, a ocorrência do reflexo orientado e da ativação de respostas a determinados estímulos novos, que se extinguem paulatinamente na medida em que ocorre a adaptação. Corresponde aos casos em que a atenção do homem é atraída por estímulos fortes, novos ou interessantes (que estejam de acordo com as necessidades) (Luria, 1979a). Na atenção involuntária, além das reações de orientação ocorridas mediante a apresentação de estímulos atrativos, como sons e cores diferenciados, é também possível medir, no bebê, mudanças no ritmo respiratório, constrição dos vasos sanguíneos periféricos e dilatação dos vasos sanguíneos da cabeça (Luria, 1979b).

Contudo, a atenção involuntária não é capaz de organizar o comportamento do sujeito. É responsável por despertar o interesse para algo, mas não se mantém por muito tempo. Vigotski e Luria (1930/1996b) observam que, caso existisse apenas a atenção involuntária, em longo prazo, não seria possível construir uma forma estável de comportamento, visto que, a cada novo estímulo, seria necessário reorganizar a conduta. E salientam, ainda, que, em tais condições, a existência apenas da atenção involuntária somente satisfaz o organismo quando este se encontra fora das exigências sociais, da cultura, do trabalho, do coletivo; pois, quando o indivíduo está inserido em um contexto que exige o desempenho de tarefas organizadas, há a necessidade da existência de formas mais estáveis de atenção. 
Assim, a história da atenção voluntária está intimamente ligada ao desenvolvimento cultural do ser humano. Esta surge, segundo Vygotski (1931/2000c), pelo esforço de domínio da atenção para a execução de uma atividade, e esse esforço não existe se o mecanismo da atenção funciona de forma automática. Com o esforço de dominar e orientar a própria atenção, ocorre um grande trabalho interno do sujeito, que pode ser medido mediante a resistência da atenção voluntária.

Leontiev (1932/1994) complementa essa ideia ao expor que, na história do desenvolvimento do comportamento voluntário, os homens das tribos primitivas, quando saíam para exercer a atividade da caça, precisavam submeter o controle do próprio comportamento de acordo com a organização estabelecida para o grupo a fim de garantir a caça. A atividade de trabalho consistiu em algo indispensável para o desenvolvimento da atenção, enquanto que esta se tornou imprescindível para o desenvolvimento da atividade de trabalho desdobrada nesses povos primitivos.

Algo semelhante ocorre com a criança nos estágios iniciais de desenvolvimento, quando se atrai sua atenção, ela é direcionada; no entanto, esta ainda não pode ser encarada como uma forma superior de comportamento, visto que é condicionada pelo estímulo externo ou uma influência direcionada de outrem e não uma forma voluntária de comportamento (Leontiev, 1932/1994).

Inicialmente, na criança pequena, os atos voluntários, dentre eles a capacidade de focar a atenção voluntariamente, têm caráter passivo, por não ter ainda a formação da linguagem simbólica completada. A criança divide seus atos voluntários com a linguagem da mãe que lhe indica objetos e nomeia-os, e a criança realiza a ação de pegá-los. Com o desenvolvimento da linguagem da própria criança, suas ações passam a ter caráter ativo, já que ela mesma pode nomear objetos, identificá-los e destacá-los dentre tantos outros que estejam a sua volta. "A ação, antes compartiIhada por duas pessoas, se converte em procedimento de organização da atividade psíquica, a ação interpsicológica adquire uma estrutura intrapsicológica" (Luria, 1979c, p. 58).

Ou seja, é na interação com a figura cuidadora que a criança transcorre a primeira etapa do domínio da linguagem e, por sua vez, da atenção. A mãe orienta a atenção da criança quando lhe pede, indica ou pergunta alguma coisa ("busca a bola", "olha a árvore", etc.). Com isso, a mãe reorganiza a atenção da criança e, "(...) separando a coisa nomeada do fundo geral, organiza com a ajuda de sua própria linguagem os atos motores da criança" (Luria, 1986, p. 95). Neste processo, o ato motor da criança divide-se entre duas pessoas: a criança e a mãe. Tem início com as alocuções da mãe e termina com as ações da criança.

Em etapa posterior do desenvolvimento, na qual a criança já é capaz de dominar a língua, começa a dar ordens a si própria. A princípio, estas ordens ocorrem de forma extensa, porque a linguagem ainda é externa; como mais adiante a linguagem é interiorizada pela criança, as ordens acontecem de forma abreviada e interna. A linguagem interna tem a função de regulação da conduta, com isso, desen- volve-se a ação voluntária consciente na criança, mediada pelo pensamento verbal, conforme Luria (1986).

\section{Das possibilidades educativas que se abrem na contramão da concepção hegemônica}

O exposto até o momento propicia embasamento para reafirmar que os problemas de desatenção e comportamentos hiperativos diagnosticados nas crianças atualmente como TDAH estão vinculados às formas de transmissão social dos comportamentos e, por conseguinte, das funções psicológicas superiores. Desenvolvem-se devido à desregulação da conduta da criança em seu processo de desenvolvimento por parte daqueles que a educam, tanto formalmente quanto informalmente, e não como decorrentes de problemas orgânicos, individuais, que os sujeitos trazem consigo em sua genética; posto que, para a Psicologia Histórico-Cultural, o indivíduo organiza sua conduta a partir do que Ihe é transmitido no seu ambiente sociocultural, condutas, hábitos e comportamentos são apropriados pela criança.

Em outras palavras, há que se considerar a qualidade das mediações e os signos e instrumentos culturais a que o sujeito teve acesso no percurso de seu desenvolvimento. Vygotski (1931/2000c) considera que a atenção voluntária é um processo de atenção mediada, fixada interiormente; e tal processo fica subordinado a leis gerais do desenvolvimento cultural e à formação de formas superiores de conduta. Isso significa que a atenção voluntária, tanto em sua composição quanto em sua estrutura e função, não é simplesmente o resultado de um desenvolvimento natural, orgânico, trata-se do resultado da mudança e reestruturação do processo natural de atenção por intermédio da influência de estímulos-meios externos. Nesse sentido, destaca-se a importância da educação e do ensino sistematizado como transmissor desses estímulos-meios externos que irão reorganizar a conduta da criança.

A atenção voluntária tem como característica o fato de o sujeito estabelecer determinadas tarefas com determinados fins que deve cumprir. Para que isto ocorra, é necessário que selecione, como objeto de sua atenção, somente aquilo que é importante para o cumprimento da tarefa. $\mathrm{Na}$ atenção voluntária, a inclinação (eleição de determinados objetos) e a concentração (manter o foco de atenção no objeto da atividade) não dependem das particularidades dos objetos em si, mas sim da tarefa a qual o sujeito se propõe. Com isso, quando a atenção não está dirigida para o objeto mais atrativo dentre os demais, é necessário que o sujeito, para manter sua concentração, desenvolva certa força de vontade, capaz de manter a intensidade da atenção para a tarefa proposta, ignorando outros estímulos. Desta forma, a atenção voluntária pode ser entendida como uma manifestação da vontade (Petrovsk, 1980).

Os atos voluntários, atos que manifestam a vontade do sujeito, são aqueles que têm como objetivo alcançar um fim determinado conscientemente. Da mesma forma que 
a atenção voluntária, estes surgiram e vêm se formando juntamente com o processo de desenvolvimento do trabaIho social. Através do trabalho social e com sua atividade pessoal, o homem deve atuar não somente com o fim de satisfazer suas necessidades, senão segundo as exigências da sociedade para satisfazer as demandas da sociedade como um todo. Os fins que o indivíduo se propõe derivam das exigências sociais. Para alcançar tais fins, com frequência, tem que renunciar à satisfação de suas necessidades imediatas e reprimir seus desejos se estes estiverem em contraposição com os fins sociais propostos. Disto, derivam as dificuldades internas, comuns quando se realizam os atos voluntários. A possibilidade de superar tais dificuldades depende, sobretudo, da medida como o indivíduo compreende, conscientemente, a necessidade dos fins de significação social de determinada atividade e controle voluntariamente seu comportamento para alcançá-los.

É importante considerar que, para a Psicologia Histórico-Cultural, a atividade está vinculada aos conceitos de motivo, sentido e significado, conforme foram propostos por Leontiev (1983). De acordo com este autor, toda e qualquer atividade é eliciada e dirigida por um motivo e é a necessidade que irá criar o motivo (sendo que este nem sempre é consciente). $\mathrm{O}$ fato de o sujeito não ser ciente do motivo que o faz realizar esta ou aquela ação não significa, porém, que esses motivos estejam separados da consciência, ainda assim encontra seu reflexo psíquico na atividade originada por esses motivos, por ter um sentido pessoal ou emocional. A atividade se constitui como tal quando o indivíduo é conhecedor de seus motivos e a estes estão atribuídos sentido e significado. O sentido refere-se às impressões pessoais que o sujeito atribui ao que está sendo realizado, e o significado de uma atividade é transmitido socialmente.

Considerando o exposto, ressalta-se a importância do processo de ensino ter claro o porquê da transmissão de determinados conteúdos. Ao ensinar qualquer conteúdo ao estudante, é importante que este saiba qual a relevância daquilo que está sendo ensinado. Ao reconhecer determinado conteúdo (atividade) como necessário à sua vida, o estudante atribuirá sentido à atividade que implica no estudo daquele conteúdo e, consequentemente, fixará sua atenção e seu comportamento voluntariamente naquilo que está sendo ensinado. Exemplo disso é o processo de ensino da leitura e escrita para o aluno do ensino fundamental. Quando este compreende qual a relevância da escrita na sua vida, ou seja, que através dela pode se comunicar com os demais e pode ler o que outros escreveram, terá motivos para aprender e sentirá a necessidade de submeter seu comportamento voluntariamente para que a aprendizagem ocorra.

Cabe observar que a atenção voluntária e o controle voluntário do comportamento são funções superiores que, conforme comentado, se desenvolvem a partir das apropriações do ambiente cultural. Logo, não se pode esperar que uma criança já nos primeiros anos de atividade escolar seja capaz de fixar voluntariamente sua atenção e controlar seu comportamento. No entanto, a escola tem fundamental importância para o desenvolvimento dessas funções supe- riores, pois exige do aluno um ritmo de organização diferenciado: "o aluno deve escutar atentamente o que se diz na aula, e estar atento não somente ao que Ihe interessa, mas também para o que não tem nenhum interesse imediato para ele" (Smirnov \& Gonobolin, 1960, p. 1945).

É importante mostrar, desde muito cedo, à criança o mundo que está a sua volta, ou seja, acostumá-la a ver, ouvir e reagir aos estímulos ao seu redor. Nos escolares iniciantes, é importante que o processo de ensino se faça interessante, para isso, é preciso que haja uma boa preparação do conteúdo e do material a ser utilizado. "A utilização de quadros, desenhos, modelos, a realização de experimentos, apresentação de exemplos concretos e ilustrações da vida cotidiana, tudo isto permite atuar sobre as emoções dos escolares, tornar o ensino interessante, excitar a atenção" (Smirnov \& Gonobolin, 1960, p. 195).

Contudo, os autores advertem que a utilização de material demonstrativo exige algumas condições. Primeiramente, é necessário organizar a percepção do aluno, ensinando-lhe a perceber aquilo que exige atenção. Por exemplo, quando se apresenta um desenho a criança, deve-se pedir que encontre ou identifique algo nele. Assim o pensamento da criança é ativado e esta aprende a se manter atenta e perceber o essencial. Além disso, é importante a qualidade das explicações do professor. Exposições ricas em conteúdo, porém com apelo emocional, chamam a atenção do aluno, sobretudo quando reconhecem algum componente novo no conteúdo já conhecido (Smirnov \& Gonobolin, 1960).

Em geral, os alunos ficam atentos às explicações que Ihes são compreensíveis. Muitas vezes, o aluno deixa de prestar atenção porque não compreendeu algo, e aquilo já não tem mais significado para ele. "A atenção se fixa melhor quando se exige do aluno um trabalho mental a seu alcance, mas o obriga, no entanto, a certo esforço de sua parte" (Smirnov \& Gonobolin, 1960, p. 197).

Para o desenvolvimento da atenção voluntária, é fundamental que se crie no aluno uma atitude consciente com relação ao estudo e ao cumprimento de suas obrigações. Os autores observam que a atenção voluntária é, antes de tudo, a atenção que organiza a ação, e sendo o estudo uma atividade organizada para fins determinados, tem-se que o ensino escolar é o melhor meio para educar a atenção voluntária. Contudo, é indispensável que o estudante compreenda a importância que a atenção tem para que ocorra sua aprendizagem. "Se o aluno compreende com clareza o que o professor quer e para que é necessária determinada tarefa, estará muito mais atento" (Smirnov \& Gonobolin, 1960, p. 197).

\section{Considerações Finais}

O artigo apresentado não pretende negar a existência de crianças desatentas e agitadas, especialmente no

5 Não há edições e/ou traduções mais atuais destes autores soviéticos que abordam questões relativas à pedagogia partindo do viés da Psicologia Histórico-Cultural. 
contexto escolar. Tampouco pretende desmerecer o esforço de profissionais que trabalham com estas crianças. $O$ interesse maior é o de problematizar o TDAH como um transtorno de ordem biológica, bem como questionar o tratamento para os casos "diagnosticados" que, em sua maioria, são feitos à base de medicamentos. A intenção é, a partir do entendimento de desenvolvimento da atenção apontado pela Psicologia Histórico-Cultural, propor outro olhar para esses casos e uma nova direção para a investigação do mesmo fenômeno, que enfoque o desenvolvimento humano sob outro prisma, que não somente o maturacional.

Olhar este que não se mantenha centrado no organismo do indivíduo, mas no ambiente cultural do qual faz parte e na qualidade das mediações que recebe. Em se tratando do ambiente cultural, cabe ponderar que se vive hoje no contexto socioeconômico permeado por políticas neoliberais, que vêm gerando transformações tanto no âmbito do trabalho quanto educacional. A exigência posta aos indivíduos neste contexto é a de que sejam cada vez mais flexíveis e adaptáveis às mais variadas situações, principalmente em decorrência dos altos índices de desemprego e trabalho informal.

Na esfera do trabalho, a economia neoliberal favoreceu a implantação de um ritmo diferenciado de atividade. Possibilitou a flexibilização dos serviços ao atrelar a produção às demandas de mercado, em que se produz o que é necessário com o mínimo de excedente. Nessa nova modalidade de produção, é exigido do trabalhador cada vez mais flexibilidade no desempenho de suas tarefas. Ou seja, o sujeito tem que dar conta de uma série de atividades e, em muitos casos, recebe gratificações de acordo com seu desempenho, o que, não raro, implica em mais dedicação ao trabalho, uma vez que uma das consequências da abertura às políticas neoliberais é a redução dos salários, assim, o trabalhador acaba dedicando-se mais para conseguir gratificações como forma de complementar sua renda (Antunes, 2006). A flexibilidade exigida nesse novo modelo de trabalho vem acarretando esfacelamento das funções mentais, dentre elas a atenção, constituindo indivíduos "multifocais". Porém, parece mais conveniente "definir" que o TDAH também acomete indivíduos adultos a repensar as questões supracitadas. O indivíduo que não consegue produzir dentro dessa lógica de produção acaba recebendo diagnóstico de TDAH e tratado com medicamentos capazes de resolver esse "déficit” produtivo. Retomando, pois, as indagações anteriores, parece que o critério posto, que define o que é saudável e patológico no sujeito "multifocal", é sua capacidade ou não de gerar "dividendos".

O objetivo principal deste artigo foi discutir o desenvolvimento da atenção voluntária desde a infância e criar novas possibilidades de entendimento sobre o "não desenvolvimento" ou "desenvolvimento parcial", como é o caso das crianças diagnosticadas, mas cabem ponderações sobre a consequência disto em adultos. Considerando que estes adultos vivem neste cotidiano conturbado de trabalho e participam da educação das crianças, e, conforme exposto anteriormente, a atenção voluntária começa a se desenvol- ver já nos primeiros anos, na convivência com as figuras cuidadoras, dependente, pois, da qualidade de tais mediações, é possível projetar o impacto que terá no desenvolvimento infantil o "modelo multifocal" característico de grande parte dos adultos na atualidade.

No que tange à educação formal das crianças, no âmbito educacional, observa-se também esta forte influência do modelo político-econômico neoliberal. A educação vem recebendo a "missão" de preparar alunos para o mercado de trabalho, porém isso ocorre apenas na aparência, pois o que ocorre de fato é que não há mercado de trabalho para todos, logo, apenas alguns terão sucesso e os que fracassarem serão responsabilizados individualmente por isso, visto que a escola apenas aparentemente cumpriu com o seu papel (Gentilli, 1998).

Além disso, neste direcionamento dos ensinamentos escolares para o mercado de trabalho, ou à exclusão dele, implicando na superficialização dos conteúdos, o aluno não é preparado para repensar ou transformar a sociedade, mas sim para se adaptar a ela (Martins, 2004). O ideário de conhecimento difundido na educação, atualmente, propõe o desenvolvimento de um conhecimento adquirido por meio da ação, da utilização e da interação. Esse modelo ficou conhecido como saber fazer, saber usar e saber comunicar. Ou seja, os indivíduos devem desenvolver todas essas capacidades em sua formação, mas devem aprender a desenvolvê-las, devem "aprender a aprender" (Rossler, 2007). É o fenômeno que Gentili (2004) denomina de "macdonaldização" da escola, organizada conforme as linhas de produção dos fast foods.

Quando se fala em TDAH, parece coerente e relevante propor que se considerem os fatores mencionados. Ao que tudo indica, os problemas de desatenção e de comportamentos hiperativos remetem antes a essa falta de direcionamento, de sistematização dos conteúdos a serem apropriados, e também às práticas de flexibilização dos serviços que atingem os mais variados tipos de trabalho.

Tendo como norte teórico a Psicologia Histórico-Cultural e seu entendimento de como se dá o desenvolvimento humano, evidencia-se que, ao se discutir problemas de desatenção e comportamentos hiperativos, antes há que se questionar quais as possibilidades de desenvolvimento da atenção no atual estágio de desenvolvimento da sociedade, uma vez que esta teoria não descarta os componentes biológicos no desenvolvimento do sujeito, mas explica que estes são superados por apropriações feitas a partir do ambiente cultural.

Este novo enfoque abre a possibilidade de um entendimento diferenciado sobre o problema da desatenção e dos comportamentos hiperativos e, ao fazer isto, possibilita questionar o entendimento hegemônico que localiza o TDAH como um problema no organismo do sujeito e reconhece que este deve ser tratado primordialmente com medicamentos. $\mathrm{E}$, além disso, tal enfoque oferece novas perspectivas para a pesquisa (teórica e de campo) em relação ao desenvolvimento da atenção voluntária, permitindo o aprimoramento de 
práticas psicológicas e educativas capazes de promover os processos atencionais em crianças, adolescentes e adultos.

Práticas que partam da premissa de que há uma unidade indissociável entre indivíduo/sociedade e entre biológico/cultural e de que o ser humano é capaz de transformar-se à medida que faz novas apropriações vão requerer o aprofundamento teórico ainda mais radical referente aos pressupostos norteadores da Psicologia Histórico-Cultural. Neste sentido, alguns desafios se colocam aos pesquisadores atuais: a fidelidade aos pressupostos marxistas e o acesso às fontes dos autores elaboradores desta teoria e seus continuadores, muitas delas apenas acessíveis em russo. Assim, este trabalho também demonstra que muito há para se fazer em pesquisas voltadas a esta temática à luz da abordagem proposta, principalmente buscando revelar a importância central das mediações necessárias para a promoção do desenvolvimento e formação da atenção voluntária da infância à idade adulta.

\section{Referências}

Antunes, R. (2006). A era da informatização e a época da informalização: riqueza e miséria do trabalho no Brasil. Em R. Antunes (Org.), Riqueza e miséria do trabalho no Brasil (pp.1525). São Paulo: Boitempo.

Argollo, N. (2003). Transtornos do déficit de atenção com hiperatividade: aspectos neurológicos. Psicologia escolar e educacional, 7(2), 197-201.

Barkley, R. A. (2008). Transtorno de déficit de atenção/hiperatividade: manual para diagnóstico e tratamento ( $3^{\mathrm{a}}$ ed., Ronaldo Cataldo Costa, trad.). Porto Alegre: Artmed.

Brown, T. E. (2007). Transtorno de déficit de atenção: a mente desfocada em crianças e adultos ( $\mathrm{H}$. Magri Filho, trad.). Porto Alegre: Artmed.

Connor, D. F. (2008). Estimulantes. Em R. A. Barkley (Org.), Transtorno de déficit de atenção/hiperatividade: manual para diagnóstico e tratamento (pp. 620-659, $3^{\text {a }}$ ed.). Porto Alegre: Artmed.

DSM IV-TR. (2003). Manual diagnóstico e estatístico de transtornos mentais ( $4^{\mathrm{a} e d}$., Texto revisado). Porto Alegre: Artes Médicas.

Eidt, N.M. (2004). Transtorno de déficit de atenção e hiperatividade: diagnóstico ou rotulação. Dissertação de Mestrado em Psicologia Escolar, Pontifícia Universidade Católica de Campinas, Campinas, São Paulo.

Gentili, P. (1998). Educar para o desemprego: a desintegração da promessa integradora. Em G. Frigotto (Org.), Educação e crise do trabalho: perspectivas de final de século (pp. 76-99). Petrópolis, RJ: Vozes.

Gentili, P. (2004). Neoliberalismo e Educação: manual do usuário.
Revista Escola e Desigualdade Social, Caderno I, 37-51.

Goldstein, S., \& Goldstein, M. (1996). Hiperatividade: como desenvolver a capacidade de atenção na criança. Campinas, SP: Papirus.

IDUM - Instituto brasileiro de defesa do usuário de medicamentos. (2009). Aumenta em 1.616\% o consumo da droga da obediência. Recuperado: 01 jun. 2009. Disponível: http://www.idum.org.br/ noticia53.html

Knapp, P., Rohde, L. A., Lyszkowski, L., \& Johannpeter, J. (2002). Terapia cognitivo comportamental no transtorno de déficit de atenção/hiperatividade: manual do terapeuta. Porto Alegre: Artmed.

Konder, L. (1985). O que é dialética (11ª ed.). São Paulo: Brasiliense.

Leite, H. A. (2010). O desenvolvimento da atenção voluntária na compreensão da Psicologia Histórico-Cultural: uma contribuição para o estudo da desatenção e dos comportamentos hiperativos. Dissertação de Mestrado, Universidade Estadual de Maringá, Maringá, Paraná.

Leontiev. A. N. (1983). Actividad, consciencia e personalidad. Havana: Pueblo y Educación.

Leontiev, A. N. (1994). The development of voluntary attention in the child. Em L.S Vigotski, The Vigotsky reader (pp. 288-312). Edited by René van der Veer and Jaan Valsiner. (Obra original publicada em 1932)

Luria, A. R. (1979a). Atenção e memória. Em A. R. Luria, Curso de Psicologia Geral (Volume III). Rio de Janeiro: Civilização Brasileira.

Luria, A.R. (1979b). La atencion (M. Torres, trad.). Em A. R. Luria, El cerebro em ación (pp. 254-276). Barcelona: Fontanela.

Luria, A. R. (1979c). Las funciones psíquicas superiores del hombre y el problema de su localizacion. Em A. R. Luria, El cérebro humano y los processos psíquicos: analisis neuropsicológica de la actividade consciente (pp. 53-66). Barcelona: Fontanela.

Luria, A. R. (1986). Pensamento e linguagem: as últimas conferências de Luria. Porto Alegre: Artes Médicas.

Markus, G. (1974). Teoria do conhecimento no jovem Marx. Rio de Janeiro: Paz e Terra.

Martins, L. M. (2004). Da formação humana em Marx à crítica da pedagogia das competências. Em N. Duarte (Org.), Crítica ao fetichismo da individualidade (pp. 53-73). Campinas, SP: Autores Associados.

Mattos, P., Palmini, A., Salgado, C. A., Segenreich, D., Grevet, E., Oliveira, I. R., e cols. (2006). Painel brasileiro de especialistas sobre diagnóstico do transtorno de déficit de atenção/hiperatividade 
(TDAH) em adultos. Rev. Psiquiatria do Rio Grande do. Sul, 28(1), 50-60.

Moraes, C., Silva, F. M. B. N., \& Andrade, E. R. (2007). Diagnóstico e tratamento de transtorno bipolar e TDAH na infância: desafios na prática clínica. Jornal brasileiro de psiquiatria. 56(I.1), 19-24.

Petrovsk, A. (1980). La atención. Em Psicologia general - manual didático para los institutos de pedagogia (pp.170-187). Moscú: Progresso.

Rossler, J. H. (2007). Trabalho, educação e psicologia na sociedade contemporânea: a formação do indivíduo no contexto da atual reestruturação produtiva. Em M. E. M. Meira \& M. G. D. Facci (Orgs.), Psicologia Histórico-Cultural: contribuições para o encontro entre a subjetividade e a educação (pp. 93-116). São Paulo: Casa do Psicólogo.

Smirnov, A. A., \& Gonobolin, F. N. (1960). La atencion (Florêncio Villa Landa, trad.). Em A. A. Smirnov, S. L. Rubinstein, A. N. Leontiev \& B. M. Tieplov (Orgs.), Psicologia (pp. 177-200). México: Tratados y Manuales Grijalbo.

Souza, I. G. S., Serra-Pinheiro, M. A., \& Fortes, D. (2007). Dificuldades no diagnóstico de TDAH em crianças. Jornal brasileiro de psiquiatria, 56(I.1), 14-18.

Vigotski, L. S. (1996). O significado histórico da crise da psicologia: uma investigação metodológica. Em L. S. Vigotski, Teoria e método em psicologia (pp. 203-420). São Paulo: Martins Fontes. (Obra original publicada em 1927)

Vygotski, L. S. (2000a). Análisis de las funciones psíquicas superiores. Em L. S. Vygotski, Obras escogidas (tomo III, Cap. 3, pp. 97-120). Madrid: Visor. (Obra original publicada em 1931)

Vygotski, L. S. (2000b). Génesis de las funciones psíquicas superiores. Em L. S. Vygotski, Obras escogidas (tomo III, pp. 139168). Madrid: Visor. (Obra original publicada em 1931)

Vygotski, L. S. (2000c). Dominio de la atención. Em L. S. Vygotski, Obras escogidas (tomo III, pp. 213-245). Madrid: Visor. (Obra original publicada em 1931)

Vygotski, L. S. (2004). A transformação socialista do homem (N. Dória, Trad.). URSS: Varnitso. Recuperado: 15 mar. 2008. Disponível: http//:www.marxistts.org/. (Obra original publicada em 1930)

Vigotski, L. S., \& Luria, A. R. (1996a). O Homem primitivo e seu comportamento. Em L. S. Vigotski \& A. R. Luria, Estudos sobre a história do comportamento: símios, homem primitivo e criança (pp. 93-149). Porto Alegre: Artes Médicas.

Vigotski, L. S., \& Luria, A. R. (1996b). A criança e seu comportamento. Em L. S. Vigotski \& A. R. Luria, Estudos sobre a história do comportamento: símios, homem primitivo e criança (pp. 151-238). Porto Alegre: Artes Médicas.

\section{Sobre as autoras}

Hilusca Alves Leite (hilusca.leite@yahoo.com.br)

Universidade Estadual de Maringá

Av. Cerro Azul, 1633, apt. 602. Maringá-PR. CEP: 87010-000

Silvana Calvo Tuleski (silvanatuleski@gmail.com)

Universidade Estadual de Maringá

Rua Francisco Glicério, 517, apto 22, Zona 07, Maringá-Pr, CEP 87050-030

Trabalho derivado da dissertação de mestrado intitulada $O$ desenvolvimento da atenção voluntária na compreensão da Psicologia HistóricoCultural: uma contribuição para o estudo da desatenção e dos comportamentos hiperativos que contou com o auxílio financeiro da CAPES. 